\title{
SABEMOS LO QUE QUERMOS. Estrategias comunitarias como respuesta a la crisis en el barrio de El Realejo
}

\author{
Yolanda CANO CABRERA \\ Universidad de Granada (España) \\ ycano333@gmail.com
}

\begin{abstract}
WE KNOW WHAT WE WANT. Community strategies in response to the crisis in El Realejo district
\end{abstract}

Resumen: La crisis económica que se está viviendo en España ha puesto en evidencia nuestro sistema político, ya que desde las distintas instituciones no se está dando una respuesta adecuada a la ciudadanía en la resolución de distintas problemáticas sociales. En el Barrio del Realejo, en Granada han surgido expresiones vecinales cuyas prácticas colectivas tratan de solucionar los efectos sociales provocados por la crisis económica, y que cuestionan el papel del Estado y de las instituciones que lo representan al no dar respuestas a la ciudadanía. Estas expresiones comunitarias deben ser tenidas en cuenta, si se quiere alcanzar un verdadero desarrollo local en el que las personas involucradas sean agentes de sus condiciones de vida.

Abstract: The economic crisis we are living in Spain has shown our political system, since from the various institutions, not being given an adequate response to the public in solving various social problems . In the neighborhood of Realejo in Granada neighborhood have emerged expressions whose collective practices trying to solve social effects caused by the economic crisis, and questioning the role of the state and the institutions that represent it by not giving answers to citizens. These community expressions must be taken into account if we are to achieve real local development in which the people involved are agents of their living conditions .

Palabras clave: Estrategias comunitarias. Crisis. Desarrollo. Antropología. Participación Community strategies. Crisis. Development . Anthropology. Participation 


\section{Introducción}

La crisis que está viviendo la sociedad española no es solo una crisis económica, sino también, es una crisis política, puesto que la sociedad ha perdido su credibilidad en la misma. Algunos autores, como Touraine (2011), lo acuñan como "crisis de la representatividad" debido a la pérdida de credibilidad en el Estado. En la sociedad española se produce una dicotomía, pues al mismo tiempo que se pide mayor democracia, por otro lado se rechazan las instituciones que la representan.

Alan Touraine (2011) expone que la actual crisis nace de una separación entre la economía financiara y la economía real que no puede separarse de la conflictividad social y de la intervención del Estado. Todo ello, sumado a la globalización, pone entre dicho el papel del Estado al distanciarse de la vida social, cultural, política y de las economías locales.

El proceso de globalización e identidad está marcado por la tensión existente entre la reestructuración de las formas políticas existentes y nuevos proyectos que apuntan a un nuevo modelo de sociedad que se desarrolla por la tensión existente entre la crisis institucional, la forma tradicional del Estado-Nación y el proceso de globalización, desarrollando nuevas identidades debido a que los agentes sociales no encuentran sentido a una identidad colectiva (Castell, 2005).

En los países pobres y de desarrollo tardío, surgieron las iniciativas de desarrollo local como estrategia para neutralizar los efectos negativos sobre el nivel de vida de la población debido a la globalización y al ajuste productivo. El resultado de las iniciativas de desarrollo local están condicionadas por el potencial de desarrollo existente en el territorio y también, por la capacidad de organización de los actores locales (Vázquez, 2009).

\section{Contexto Etnográfico}

El Barrio del Realejo se encuentra en el casco viejo de la ciudad de Granada, en el distrito Norte y en la parte suroriental de la Alhambra. Se sitúa a la orilla izquierda del río Darro, extendiéndose desde la Plaza Isabel la Católica a las vistillas de los cerros del Sol y de los Mártires. En la explanada del rio Genil se extienden San Matías, el Realejo y las Angustias, tres enclaves de diferente origen histórico, unidos por la urbanización de la ciudad de Granada (Fernández, 2002).

Es un barrio habitado por personas de diferentes culturas debido a su atracción turística. Al caminar por sus calles, encontramos a personas de diversas nacionalidades. También, se pueden encontrar a muchos estudiantes atraídos por el Centro de Lenguas Modernas y estudiantes con Becas Erasmus. Y además, personas que se han establecido en el barrio como consecuencia de su proceso migratorio o simplemente, artistas que buscan un lugar idílico en el que inspirarse. La convivencia multicultural en el Barrio del Realejo se presenta sin conflictos y más bien, una vez asentadas las personas en el barrio adoptan una identidad "nueva" como vecinos y vecinas del mismo, relacionándose con respeto a las diferencias culturales.

\section{Estrategias colectivas de los vecinos y vecinas}

En el Barrio del Realejo, en Granada han surgido expresiones vecinales cuyas prácticas colectivas se encaminan a solucionar problemáticas sociales provocadas por la crisis económica, y que cuestionan el papel del Estado y de las instituciones que lo representan al no dar respuestas a la ciudadanía. A través, de distintos testimonios encontramos estrategias colectivas que las personas que habitan en el Barrio del Realejo utilizan para mejorar sus condiciones de vida. Entre estas estrategias colectivas encontramos algunas como ésta, impulsada por los bares situados en el Campo del Príncipe, en el Barrio del Realejo, 


\begin{abstract}
"Veo en la barra del bar del bar un folleto publicitario en el que figuran los nombres de los bares situados en Campo Príncipe. [...] Le pregunto a Arancha, quién ha promovido todo esto. Me comenta que ha surgido de forma espontánea entre los dueños de los distintos bares de la plaza, ante la necesidad de movilizarse y promocionar la zona. Que hace 2 años, se montó una Asociación de Comerciantes y que se vino abajo porque la gente está muy dividida y no se ponen de acuerdo" (Diario de Campo. Bar las Niñas, 26 de noviembre del 2013).
\end{abstract}

En este testimonio vemos una clara intención de los comerciantes del Barrio del Realejo en asociarse para dinamizar la zona. Y así, intentar mejorar sus economías locales, sin embargo, la iniciativa ha quedado frustrada ante la falta de acuerdos entre las personas asociadas. Esta iniciativa frustrada, muestra la imposibilidad de materializar objetivos colectivos, dadas las disputas entre vecinos y vecinas. Y también, nos muestra la ausencia de implicación de las instituciones locales cuya intervención y apoyo podría haber contribuido al impulso de acciones colectivas para dinamizar el comercio local, en este caso concreto, la dinamización de los comercios del Campo del Príncipe, en el Barrio del Realejo.

Para Burton (1990) hay que distinguir entre "disputas" y "conflictos". Los conflictos están relacionados con antagonismos entre las partes implicadas debido a elementos estructurales de desigualdad y de poder. Para solucionar el conflicto se hace necesario eliminar esos elementos, es decir, se debe producir una transformación, mientras que las disputas se relacionan con enfrentamientos coyunturales debido a la diferencia de necesidades, valores y/o intereses, pudiéndose solucionar, a través de la negociación o de la mediación.

Giménez (2009) distingue tres tipos de sociabilidad, la convivencia, la coexistencia y la hostilidad. La convivencia se daría cuando se da armonía entre las relaciones, la ocupación y en el uso de los espacios no existe una separación marcada en función del grupo étnico y/o nacional, además de existir mecanismos para regular los conflictos. En cuanto a la coexistencia, existe una separación entre los grupos, las interacciones se limitan a lo imprescindible, evitando el conflicto abierto y sin abordarlo. La hostilidad se da cuando existen enfrentamientos, entre los grupos, desconfianza y mala comunicación, sin mecanismos que regulen el conflicto.

Las disputas entre el vecindario del Barrio del Realejo inciden en que no haya una sociabilidad que les permita participar colectivamente en la consecución de objetivos comunes que puedan mejorar su calidad de vida. Aunque, las personas del barrio coexisten, no resuelven los conflictos que impiden una convivencia en la que se compartan los espacios de una forma armoniosa que beneficie al vecindario.

El desarrollo de un territorio o localidad requiere la coordinación de los actores públicos y privados en la ejecución de sus programas de intervención (Vázquez, 2009).

\title{
Estrategias institucionales
}

Entre las estrategias institucionales para mejorar la vida colectiva en el Barrio del Realejo encontramos el testimonio del Concejal de Participación Ciudadana del Ayuntamiento de Granada,

"Mejorar el acceso al barrio, rescatar lo que hay de tradicional" (E.11. Vicente Aguilera, Concejal de Participación Ciudadana del Ayuntamiento de Granada, 3 de mayo del 2013).

La difusión de las innovaciones y el conocimiento de la producción local es otro de los ejes principales en las políticas de desarrollo local, ya que pueden permitir la apertura de 
nuevos mercados (Vázquez, 2009). Sin embargo, las mejoras que se proponen desde la Concejalía de Participación Ciudadana del Ayuntamiento de Granada para contribuir a la dinamización del Barrio del Realejo no llegan a materializarse, a pesar de que estas medidas podrían mejorar el tejido productivo local y beneficiar no solo al Barrio del Realejo, sino a la ciudad de Granada dónde está circunscrito este barrio. Todo ello, a pesar de tener antecedentes sobre numerosos proyectos de desarrollo local que han dado resultados positivos en regiones de Latinoamérica.

En cuanto a la mejora de acceso al Barrio del Realejo. la única solución llevada a cabo a nivel institucional, ha sido construir un parking provisional en uno de los patios del Colegio Ave María Vistillas, tras meses de desencuentros entre el Ayuntamiento y la Junta de Andalucía, ante el intento del Ayuntamiento de Granada de construir un parking subterráneo de tres plantas en el Colegio Torres Hurtado.

La iniciativa privada, ha sido propuesta por la Fundación Patronato Avemariano quien gestionará la explotación del parking. A pesar de esta medida, el vecindario se ha quejado, pues no hay bonos de parking para ellos y el parking está siendo utilizado mayoritariamente por turistas según expresan. Además de ello, según testimonio de algunos vecinos y vecinas del Barrio del Realejo, han recortado las líneas de autobús público que conectaban el barrio con la ciudad, considerando que el transporte público sería una solución más ecológica y sostenible para ellos porque a un barrio prácticamente peatonal, se debería acceder andando o en bici.

Por otro lado, las personas que habitan en el Barrio del Realejo, acogen con entusiasmo la apertura de la Escuela Técnica Superior de Arquitectura en Campo Príncipe que atraerá al barrio a más de 1.700 estudiantes y más de 100 profesores y profesoras. La apertura de este recinto universitario es vista por el vecindario como una salida a la situación de estancamiento del barrio, ya que esperan que mejore el consumo en los bares de la zona, se incremente el precio del alquiler de las viviendas, que había caído un 20 por cien durante la crisis y además, atraiga más comercios.

Para Vázquez Barquero (2009) la crisis financiera en los países avanzados y emergentes ha provocado que el sistema bancario ya no sea quién dinamice el sistema productivo. Y aunque, todavía se desconoce el alcance de la situación, la falta de liquidez e insolvencia de los bancos no permiten que el crédito fluya hacía las empresas y el sistema productivo, provocando el cierre de negocios y destrucción del empleo. Todo ello, señala al desarrollo local como una vía de salida a la crisis económica, puesto que, permitiría realizar un ajuste productivo desde una perspectiva territorial dando respuestas concretas a problemáticas específicas buscando el progreso social y un desarrollo sostenible.

En la ciudad de Granada, sin embargo, el Plan Estratégico de Desarrollo se efectuó en el año 2000 y con una vigencia hasta el año 2006. El documento emanó del Consejo Económico y Social de la ciudad y su objetivo principal consiste en promover el desarrollo económico de la ciudad (Ayuntamiento de Granada, 2000).

El Plan de Desarrollo de Granada se articula en tres ámbitos de actuación: La iniciativa URBAN, apoyo a las empresas y subvenciones. En la dicha iniciativa, financiada por los fondos europeos FEDER estaba destinada al casco histórico de Granada, incluyendo los barrios de Albaicín y Sacromonte para mejorar el hábitat urbano, la integración social, el desarrollo sostenible y la participación ciudadana.

El apoyo a las empresas estaba basado en la unificación de trámites y el establecimiento de un entorno de confianza para la creación, y mejora del tejido empresarial. Y algunas ayudas y subvenciones para promover el deporte y algunos proyectos relacionados con la mujer entre otras. En el 2007, se presenta "El Plan Estratégico", un documento marco con la finalidad de ofrecer oportunidades de desarrollo a la ciudad de Granada, en virtud del Preámbulo y el artículo 131 de la Ley 57/2003, de 16 de diciembre de medidas para la modernización de los gobiernos locales (Ayuntamiento de Granada, 2007). 
Este documento es el resultado del trabajo iniciado por el Consejo Económico Social de Granada y posteriormente, continuado por el actual Consejo Social de la Ciudad de Granada. La finalidad del mismo es ampliar las posibilidades de la ciudad con las aportaciones de la ciudadanía, las entidades públicas y privadas bajo los principios de transparencia, valoración del conocimiento en Granada, participación ciudadana, rigor técnico, coherencia, posibilismo, medidas integradoras y una visión metropolitana (Ayuntamiento de Granada, 2007).

El "Plan de Desarrollo" de Granada, ha sido desarrollado con una amplia participación en conexión con otros planes e iniciativas como; los planes e iniciativas autonómicas, el ámbito empresarial y social, las instituciones granadinas y los planes e iniciativas locales (Ayuntamiento de Granada, 2007).

Los ejes estratégicos del "Plan Estratégico" son: Consolidar a Granada como referente cultural, conseguir que Granada sea una ciudad sostenible y con un tejido productivo integrado e identificar y caracterizar Granada como referente de calidad de vida. Y como objetivo, se ha priorizado la implicación y la participación de la ciudadanía en un clima de colaboración, diálogo y consenso, a través de los mecanismos establecidos.

El "Plan Estratégico" ha contado con diferentes acuerdos con grupos de investigación de la Universidad de Granada, Instituciones de Música, Bellas Artes, Creatividad Cultural y Ciencias de la Salud, además de acuerdos con Colegios Profesionales (Ayuntamiento de Granada, 2007).

Para conocer la situación de ciudad de Granada, se realiza un análisis DAFO que busca una orientación a la hora de tomar decisiones en cinco ámbitos que son considerados estratégicos en el desarrollo futuro de la ciudad. Estos cinco ámbitos son: La cultura y el ocio, el desarrollo económico y tejido el productivo, las infraestructuras en movilidad y el transporte, el bienestar social y el medioambiente y el desarrollo sostenible.

El "Plan Estratégico" cuenta con un conjunto de líneas estratégicas muy interesantes, sin embargo llama la atención que este documento, no haya integrado a la Diputación de Granada, ya que ésta forma parte de la Agenda 21 de la Cultura de Barcelona, tampoco se hace mención del Barrio del Realejo, lugar con un gran patrimonio cultural. Además, no recoge la incidencia de las actividades artísticas en el espacio público cuyas expresiones son parte del patrimonio cultural de la ciudad de Granada, ni tampoco la participación de asociaciones no institucionalizadas.

En cuanto a los modelos de gestión y de políticas de intervención urbana, hay dos perspectivas distintas determinadas por la crisis urbana. Una de ellas, apuesta por superar la crisis profundizando en la privatización, considerando el espacio público como un freno, como algo marginal. Y la otra, considera el espacio público como una forma de atenuar la crisis (Carrión, 2007).

La privatización del espacio público y la segmentación vivida en la ciudad provoca que, el mismo sea un ámbito de "expresión y acción" de las clases populares urbanas, contribuyendo a su "asedio y a su redefinición" (Carrión, 2007: 2). El espacio público es un concepto que va más allá de lo físico-espacial como los parques y plazas, sino que es un ámbito que contiene la conflictividad social, en función de la coyuntura y de la ciudad a la que se refiera. El concepto dominante de espacio público proviene de las corrientes de urbanismo moderno. Hace referencia a un lugar físico que es gestionado o que es de propiedad pública, sin embargo es una concepción del espacio público muy reducida, puesto que existen otras concepciones dominantes sobre el mismo.

Como expresa Carrión (2007: 5), el espacio público hay que "entenderlo históricamente como parte y en relación a la ciudad, lo cual comporta que los espacios públicos cambian por su cuenta y se transforman en relación a su ciudad".

En la actualidad, las ciudades se organizan desde el ámbito privado y los espacios comunitarios se consideran un "desperdicio" desde la lógica económica. Sin embargo, el espacio 
público como las plazas son componentes fundamentales para organizar la vida colectiva y la representación social de la ciudad (Carrión, 2007).

En el año 2009, en la ciudad de Granada, se aprueba la "Ordenanza de medidas para fomentar y garantizar la convivencia ciudadana en el espacio público de Granada", publicada en el BOP n 202, miércoles, 21 de octubre de 2009.

"El objetivo principal de la Ordenanza es el preservar el espacio público como un lugar de convivencia y civismo, en el que todas las personas puedan desarrollar en libertad sus actividades de libre circulación, de ocio, de encuentro y de recreo, con pleno respeto a la dignidad y a los derechos de los demás y a la pluralidad de expresiones y de formas de vida diversas existentes en Granada" (Ordenanza de medidas para fomentar y garantizar la convivencia ciudadana en el espacio público de Granada, 2009: 26).

La citada ordenanza considera como espacio público de la ciudad, las calles, las vías de circulación, las aceras, las plazas, las avenidas, los paseos, los pasajes, los bulevares, los parques, los jardines y zonas verdes o forestales, los puentes, los túneles y los pasos subterráneos, los aparcamientos, las fuentes y los estanques, los edificios públicos y los espacios destinados al uso y/o servicio público municipales, y también, a las construcciones, las instalaciones, el mobiliario urbano y los demás bienes y elementos del dominio público municipal situados en aquellos (Ordenanza de medidas para fomentar y garantizar la convivencia ciudadana en el espacio público de Granada, 2009).

La ordenanza contiene más de 150 artículos en los que se burocratiza la convivencia en la ciudad de Granada sin el consentimiento del Ayuntamiento de la ciudad. Entre las prohibiciones, penalizadas con multas, encontramos; "toda manifestación de arte espontáneo", es decir, no se puede tocar en la calle sin permiso del Ayuntamiento, ni tampoco, la actuación de mimos, pintores y ni siquiera, poder cantar o tocar la guitarra en un parque entre un grupo de amistades.

También, está prohibido cualquier trabajo o relación entre personas monetaria en la vía pública, dormir en la calle y pedir limosna, se regula correr y jugar a la pelota, sacudir mantas, regar macetas o colgar ropa en los balcones y ventanas, comer y beber en la calle y repartir panfletos o documentos en la calle y pegar carteles, entre otras prohibiciones, penalizadas por multas por los agentes municipales (Ordenanza de medidas para fomentar y garantizar la convivencia ciudadana, en el espacio público de Granada, 2009).

En julio del 2012, como respuesta a las multas impuestas por el Ayuntamiento a vecinos y vecinas del barrio, la Asamblea del movimiento 15M organiza un taller para tratar los límites de la Ordenanza. Entre las personas multadas, se encuentra un artista muy conocido del Barrio del Realejo, "El Niño de las Pinturas" que ha sido penalizado por pintar fachadas en el Barrio, a pesar de que la mayoría son fachadas privadas, pintadas con el consentimiento de los dueños que le han contratado.

El Niño de las Pinturas es uno de los artistas más internacionales del Barrio del Realejo. Sus obras decoran muchas fachadas del barrio y muchos turistas, se acercan al Realejo para realizar fotografías de sus grafitis. En algunas universidades españolas y europeas, realizan trabajos y tesinas sobre el estilo de este grafitero con un estilo muy característico.

Raúl es el nombre del Niño de las Pinturas. Lleva viviendo en el Barrio del Realejo diez años. Su primer grafiti lo realizó en el año 2001, en la calle Pavaneras. La mayoría de grafitis realizados por este artista tienen un mensaje social, relacionado con reivindicaciones del arte flamenco, el respeto por las personas mayores, la protección de los niños y mensajes sobre su cosmovisión de la vida.

También, fueron multados por infringir la ordenanza de convivencia unos costaleros que realizaban un ensayo de sus pasos por las calles del Barrio del Realejo (El Ideal, 27 de 
febrero del 2012). Como expone Amartya Sen (2006: 19), "el desarrollo puede concebirse como un proceso de expansión de las libertades reales de que disfrutan los individuos".

La realidad del Barrio del Realejo, situado en Granada es que con la legislación vigente, cada vez se restringen más las expresiones culturales populares y especialmente, las expresiones culturales colectivas, necesarias para que se produzca un verdadero desarrollo local, más allá de la dimensión económica.

Por ese motivo, la Asamblea Popular del Realejo y Barranco del Abogado creó en junio del 2013 unos bonos de apoyo en forma de libreta de tres euros destinados a una campaña de criminalización de la protesta social y también, a la caja de resistencia de la Asamblea, ya que según los testimonios recogidos, se expresa que la Subdelegación del Gobierno de Granada está multando a cientos de personas en Granada por salir a la calle a reivindicar derechos, protestar contra los recortes en sanidad, educación empleo, prestaciones por desempleo y vivienda. En la Asamblea se denuncia que muchas de estas multas están siendo impuestas bajo reconocimiento visual sin solicitar la documentación de las personas penalizadas.

En la Asamblea del Barrio del Realejo y Barranco del Abogado, también se ha creado una caja de resistencia para el barrio con la finalidad de asumir de forma colectiva las multas. La idea del proyecto está basada en la corresponsabilidad y la autogestión del vecindario del barrio. Las libretas se distribuyen en algunos comercios del Barrio del Realejo y también, de Granada.

Otra de las iniciativas de la Asamblea del Barrio del Realejo y Barranco del Abogado fue la campaña realizada para difundir la huelga general del 14 de noviembre del 2012. Las personas participantes realizaron carteles, panfletos informativos y vídeos de promoción para concienciar al vecindario del barrio sobre la importancia de cerrar los comercios y no ir a trabajar, además se organizaron piquetes informativos y se acordó acudir a la manifestación celebrada en Granada con motivo de la huelga general.

Desde esta Asamblea vecinal, también se crearon otras áreas temáticas que responden a la problemática y necesidades del vecindario del Barrio del Realejo, entre ellas; el Grupo de Cultura, el Grupo Laboral, el Grupo de Acción Álmate, el Grupo de Medioambiente, el Grupo de Vivienda y Desahucios y el Grupo de Autoformación (Asamblea Popular del Realejo y Barranco del Abogado, 2011).

Llama la atención, que en el mismo Barrio del Realejo, se haya formado una Asamblea que se llama a sí misma "popular" formada por vecinos y vecinas del barrio, que manifiesta inquietudes diferentes a las dos asociaciones vecinales formales situadas, también en el mismo barrio; La Asociación del Barrio del Realejo y la Asociación del Barranco del Abogado.

"En la asociación de vecinos del Realejo, hay falta de pluralidad. Solo representan a una minoría y a quiénes no piensan como ellos, les ponen trabas para entrar. Además, tiene locales del Ayuntamiento y no nos los dejan para hacer asambleas y actividades" (E. 17. Vecina del Santa Catalina, 2 de noviembre del 2012).

En los discursos del vecindario que acuden a las Asambleas Populares, se capta un antagonismo entre los "popular" y lo institucional. García Canclini (2001: 2) aborda la cuestión del concepto "popular". Para este autor, lo popular se relacionaba con la cultura indígena o el folclore. Los estudios que se realizaban desde la antropología atendían a la "pasión coleccionista y descriptiva" del folclore al considerarlo como exótico, aunque todas las descripciones y enumeraciones que se realizaban "no llegan a explicar el sentido de lo popular al no situarlo en las condiciones generales de desarrollo socioeconómico".

Muchos de los estudios realizados, al centrarse en los aspectos "puros" de grupos étnicos, dejaron a un lado, la interacción de los mismos con la "sociedad nacional y 
con el mercado económico y simbólico transnacional", obviando que estos grupos, en su interior, también reproducen el capitalismo o "construyen con él formaciones mixtas". Por otro lado, los estudios realizados sobre comunicación masiva, han definido lo popular desde otra perspectiva opuesta, definiendo la cultura popular actual, no como resultado de las "diferencias locales sino de la acción homogeneizada de la industria cultural". Aunque, la comunicación ha realizado aportaciones como la observación de otros espacios de reproducción y control social, tales como la información y el consumo, también hay que criticarle que conciban la cultura como un "instrumento del poder para manipular a las clases populares". Sin embargo, gran parte de los estudios realizados sitúan a los receptores de los mensajes transmitidos por la burguesía dominante como receptores pasivos o que actúan verticalmente imponiendo sus valores. El poder es "una relación social diseminada", así que no está situado en un "foco único de soberanía", y por tanto, no "puede estar atrapado en una institución, en el Estado o en los medios de comunicacionales". Consiste en múltiples relaciones de fuerza que actúan en "la producción y el consumo, en las familias y los individuos". Esto no significa, que el poder no se concentre principalmente, en las instituciones y los agentes sociales, ni que hay una jerarquía en las acciones realizadas por las mismas, ya que no es lo mismo el poder de las acciones ejecutadas por las empresas transnacionales que el poder ejercido por un padre de familia. Toda esta reflexión, apunta que hay que replantearse la relación entre poder y cultura popular, ya que abundan numerosos estudios sobre la reproducción de la cultura y escasean estudios en los que se aborde el impacto que tienen estos los mensajes en las clases populares (García Canclini, 2001: 2).

García Canclini (2001: 5), a partir de este discurso, cuestiona qué es lo popular, llegando a la conclusión utilizando el enfoque gramsciano, que "lo popular no se definiría por su origen o sus tradiciones, sino por su posición, la que construye frente a lo hegemónico". Así, pues, la cultura y la participación son fundamentales, en la gestión del desarrollo local, siendo uno de los pilares del desarrollo sostenible; junto al desarrollo económico, social y ambiental.

La cultura contribuye a la identidad y sentimiento de pertenencia comunitaria que implica a la población en su propio desarrollo. Sin embargo, las políticas de los Agentes de Desarrollo Local van encaminadas a gestionar un concepto de cultura basado en la organización de exposiciones, de charlas informativas, fiestas y marketing turístico entre otras. Por tanto, la cultura no solo se trata de industrias creativas o infraestructuras culturales, sino de la "expresión viva de un pueblo", y no de un objeto de consumo en el mercado (Calvo y otros, 2013: 18).

El sistema capitalista entiende que la cultura es una mercancía a la que se puede poner precio y con la cual negociar. Esta idea es legítima, siempre y cuando las personas que la producen se beneficien de ello, sin embargo la realidad es otra muy distinta, pues la cultura local suele verse alterada cuando es utilizada como atracción turística, ya que cambia sus significados (Acuña, 2004). Aquí distintas estrategias de la Asociación de Vecinos y Vecinas,

"Seguimos buscando cursos para los vecinos y vecinas, y también participamos con el banco de alimentos y ropa, pues la gente lo está pasando mal con la crisis, también colaboramos con la ONG Madre Coraje” (E.6. Julia, Presidenta Asociación Barranco del Abogado, 3 de junio del 2013).

La formación es otro de los objetivos específicos en las políticas de desarrollo local, ya que a través, de la formación de los recursos humanos se puede incorporar conocimiento que sea útil en la producción de los bienes y servicios y también, en la gestión de las estrategias de desarrollo (Vázquez, 2009). Entre la formación que se da en esta asociación de 
vecinos, encontramos talleres de manualidades, gimnasio, fisioterapia, guitarra, taller de memoria y de voluntarios de la Cruz Roja y proyectos sin especificar, además de una visita al Parque de las Ciencias y excursiones a la Ruta del Agua, la Ruta del Chocolate, a las Aguas Termales, Taller de Memoria y Voluntarios Cruz Roja.

También, desde la asociación de vecinos del Barranco del Abogado, ha elaborado una guía turística con las aportaciones de los anunciantes y comerciantes de la zona. La guía incluye un mapa con el itinerario "La Ruta de Boabdill" que oferta un paseo desde el Barranco del Abogado, hasta la Granada del Siglo XIX, explicando los distintos puntos de interés turístico. Esta ruta permite atraer a turistas interesados por la zona y a su vez, promocionar comercios del Barranco del Abogado y del Barrio del Realejo.

Las iniciativas formativas responden a las necesidades expuestas por el vecindario en las asambleas de la Asociación del Barranco del Abogado, aunque escasean o son prácticamente inexistentes iniciativas que promuevan la empleabilidad de vecinos y vecinas o iniciativas de participación sobre la gestión de sus propios recursos culturales como recurso turístico y el impacto que puede tener el mismo en la mejora de su calidad de vida o por el contrario, empeorar sus condiciones.

La crisis económica de los años 70 y los efectos que esta produjo, hicieron cuestionar el modelo de desarrollo local desde una perspectiva exógena, a través de políticas públicas como; subvenciones e inversiones a las empresas, que se instalaban o invertían en territorios, dando lugar a otro tipo de desarrollo local, basado en el potencial endógeno del territorio (Araújo y otros, 2012).

Como señala Vázquez (2000), el proceso de globalización está vinculado al territorio, puesto que afecta a las naciones y a los países, ya que la economía y el ajuste productivo están sujetos a las inversiones, la localización de actores económicos, y también a la atracción de los territorios. Por tanto, toda esta dinámica afecta al comportamiento de los actores locales. El nuevo orden internacional no se sitúa de una forma simétrica entre Centro-Periferia, tal y como se sostenía la Teoría de la Dependencia' ${ }^{1}$ (Vázquez, 2000: 3),

"La pobreza es una cuestión que no sólo afecta al Sur sino que los bajos niveles de renta, la baja capacidad tecnológica y la injusta distribución de la renta caracterizan, también, a las ciudades y regiones del Norte, si bien los niveles de pobreza en el norte y en el sur no son comparables".

En la actualidad, las transformaciones económicas, políticas, institucionales, organizativas y tecnológicas y sociales, acentuadas por la crisis económica apuntan al desarrollo endógeno como una alternativa de mejora en las economías locales. Y que apuesta por los recursos territoriales, tanto económicos, humanos, institucionales y culturales, a favor del bienestar de la comunidad con implicación de los agentes locales, ya sean públicos o privados. Como apunta Escobar (2010: 135),

"Desde una perspectiva antropológica, es importante llamar la atención sobre el emplazamiento de todas las prácticas culturales, algo que se desprende del hecho de que la cultura es llevada a los lugares por cuerpos. Así, los cuerpos son enculturizados, y a la inversa, establecen prácticas culturales. Por tanto, la identidad personal y cultural está atada a un espacio”.

1 Los economistas de la Cepal basaban su enfoque en la demostración empírica del deterioro histórico de los términos de intercambio que afectaba a los bienes primarios de los países de la periferia. Los términos "centro" y "periferia" (radicalizados en la teoría de la dependencia durante los años sesenta) fueron ideados por la Cepal como elementos de su explicación del fenómeno (Escobar, 2007: 43). 
En un trabajo de investigación realizado por Araújo; Villamarín y Fraiz (2012), tras revisar cuatro iniciativas turísticas; el Camino de Santiago (Galicia), el Parque Nacional Picos de Europa (Asturias, Cantabria y León), cultura y turismo (Sevilla) y la Campaña del litoral (Comunidad de Valencia) se pone en evidencia el papel del turismo como dinamizador socioeconómico y por tanto, de desarrollo de los territorios implicados, al utilizar como reclamo turístico las potencialidades de cada zona, respetando a la población local. Además de ello, la población local se ve beneficiada en algunos aspectos como; la mejora de las infraestructuras locales, una mejora en la imagen de la ciudad, la oferta de actividades complementarias con la zona o región, participación de los residentes y una apuesta por la sostenibilidad. Aunque como sostiene, Ángel Acuña (2004),

"el turismo, como proceso de cambio implica una transformación que, para la población local, no necesariamente se encuentra asociado al crecimiento o al desarrollo, sin embargo, la inestabilidad y la dependencia sí se hallan presentes en la adaptación de las poblaciones al proceso modificador (Nieto, 1975, crf. Acuña, 2004).

Desde los países occidentales, el turismo se considera como una solución a los problemas del subdesarrollo y en la actualidad, como una salida para crear puestos de trabajo, tras la crisis económica, sin embargo, tras la experiencia española durante los años de dictadura franquista, se pueden apreciar las consecuencias de las distintas fases de planificación turística (Acuña, 2004). Aquí se muestra otras iniciativas llevadas a cabo en el Campo del Príncipe,

"El barrio es muy grande y el corazón es Campo Príncipe que se está quedando solo. Ahora con la Concejala del Ayuntamiento, se montan mercadillos los domingos de artesanía, también el Certamen de Pintura, así se atrae gente a los bares. Las Cofradías Colaboran. Siempre están dispuestos" (E. 15. Vicepresidenta, Asociación de Vecinos el Barrio del Realejo, 3 de diciembre del 2013).

Este mercado artesanal está impulsado por la asociación granadina "Entretanto Creando" con la colaboración del Ayuntamiento de Granada, en el que se muestra artesanía moderna. Además, de esta iniciativa el Campo del Príncipe comienza a ser un espacio al aire libre en el que se muestran otras alternativas artísticas como, el Concurso de Pintura al Aire Libre y el Mercado de Arte que se impulsaron en el 2013.

Estas iniciativas, no solo repercuten económicamente a los comercios y bares en Barrio del Realejo, especialmente a los que están localizados en el Campo del Príncipe, sino que benefician a los artistas y artesanos locales. Además, también cumple otras funciones como transformarse en un lugar de encuentro social en el que los artistas, artesanos y personas que acuden a comprar o simplemente a pasear, intercambian información y también, refuerzan sus vínculos o amplían sus redes sociales.

Como podemos comprobar, a partir de este trabajo etnográfico, las estrategias comunitarias son muchas y muy variadas en el Barrio del Realejo, sin embargo, solamente algunas de ellas son apoyadas a nivel institucional. En el caso de este barrio, se apoyan mayoritariamente las iniciativas colectivas que se gestionan o potencian desde la Asociación de Vecinos del Barrio del Realejo. En los discursos de los testimonios fruto de la observación participante y de las entrevistas realizadas, se recoge la percepción en el vecindario del Barrio del Realejo sobre la relación de clientelismo entre la actual formación política del Ayuntamiento de Granada y esta asociación de vecinos. Y por otro lado, la Asociación del Barranco del Abogado, se relaciona con la formación política a nivel regional. 
Esta situación, hace que en el momento actual, muchos vecinos y vecinas del barrio no quieran participar en estos mecanismos, pues muchos de sus intereses y necesidades difieren de las decisiones que se toman a nivel institucional.

González Alcantud (1998: 191) describe el clientelismo como una forma de estructurar la sociedad que está basada en "la economía del don y el contradón, es decir, en la reciprocidad", a través de un "contrato diádico", que se acuerda entre,

"[...] dos individuos o cabezas de grupo familiar o social, por el cual se establece una relación instrumental entre patrón y cliente para acceder a los recursos disponibles, sean éstos naturales o estatales. Esa relación diádica se lleva a cabo entre desiguales sociales. El patrón en lo esencial es un intermediario político, social, económico o lingüístico, capaz de acceder a las fuentes de recursos. El cliente le ofrece al patrón apoyo político social para mantener su influencia".

Para González Alcantud (1998) el clientelismo sería una desviación u ocultamiento de la democracia que termina contradiciendo el principio de igualdad de la misma y cuyo efecto es la corrupción. En el Programa de Naciones Unidas para el Desarrollo (PNUD, 1990), entre las finalidades del desarrollo local se menciona la mejora de la vida de toda la comunidad, a través de su participación activa, dando importancia a que la iniciativas provengan de la propia comunidad.

\section{Conclusiones}

A través de este trabajo etnográfico, hemos podido comprobar que es prácticamente imposible que en el Barrio del Realejo se puedan promover mejoras en las condiciones de vida del vecindario, ya que en los mecanismos formales de participación comunitaria no se está teniendo en cuenta la pluralidad y diversidad de actores sociales del barrio, además de deslegitimar los mecanismos informales de participación.

Para que haya una transformación real a favor de la comunidad, es necesario que haya una participación activa de vecinos y vecinas en proyectos colectivos, más allá de los intereses individuales o institucionales.

\section{Bibliografía}

ACUÑA, Ángel

2004 “Aproximación conceptual al fenómeno turístico en la actualidad”, en Gaceta de Antropología, 20, art. 17.

ASAMBLEA POPULAR DEL REALEJO Y EL BARRANCO DEL ABOGADO

2012 Acta Asamblea del 23 de junio del 2013. http: //realejo-barranco.blogspot.com.es/p/actas. html. $(23 / 12 / 2014)$.

ARAÚJO, NOELIA y otros

2012 "Iniciativas turísticas y desarrollo local. Análisis de cuatro casos destacados en España", en Revista de investigación en turismo y desarrollo local, vol 5, $\mathrm{n}^{\mathrm{o}} 12$, junio.

AYUNTAMIENTO DE GRANADA

2000 Plan Estratégico de Desarrollo. http: //www.granada.org/inet/wgr.nsf/d28fcf117dfc3245c 12571730045dedc/9355fdfb277da89cc1256e31007bbe40! OpenDocument (10/02/2015).

2005 Documento Marco Plan Estratégico de Granada. Consejo Social de la Ciudad de Granada. http: //www.csgranada.com/pdf_cs/Doc_Marco_CSG.pdf (10/02/2015).

2007 Ordenanza de medidas para fomentar y garantizar la convivencia ciudadana en el espacio público de Granada. http: //www.granada.org/inet/wordenanz.nsf/0/33e8e05267172f0ec1 257656003437a2?OpenDocument (03/03/2014). 
BURTON, John

1990 Conflict: Resolution and Prevention. Londres: The Macmillan Press.

CALVO, Ricard y otros

2013 "Ciudadanía empoderada: Cultura y participación para el desarrollo local”, en IV Jornadas sobre desarrollo local de la Comunidad Valenciana. Valencia: Editorial Germania.

CARRION, Fernando

2007 "El espacio público: Punto de partida para la alteridad”, en Espacios públicos y construcción social. Hacía un ejercicio de ciudadanía. http: //works.bepress.com/fernando_carrion/174 (22/01/2015)

CASTELL, Manuel

2005 “Globalización e identidad”, en Quaderns de la Mediterránia, 5, 11-20.

EL IDEAL

2012 “Costaleros detenidos en el Barrio del Realejo". http: //www.ideal.es/granada/20120227/ local/granada/multan-cuadrilla-costaleros-granada-201202271350.html (01/04/2015).

ESCOBAR, Arturo

2007 La Invención del Tercer Mundo. Construcción y deconstrucción del desarrollo. Caracas: Fundación Editorial El Perro y la Rana.

2010 "Una minga para el postdesarrollo: lugar, medo ambiente y movimientos sociales en las transformaciones globales". Lima: Universidad Nacional Mayor de San Marcos.

GARCÍA CANCLINI, Néstor

2001 "Ni folklórico, ni masivo, ¿qué es lo popular". http: //www.infoamerica.org/documentos_pdf/garcia_canclinil.pdf (29/01/2015)

GIMÉNEZ, Carlos

2009 "El impulso de la convivencia ciudadana e intercultural en los barrios europeos: marco conceptual y metodológico"; en Marco conceptual y buenas prácticas en ciudadanía y convivencia en barrios europeos INTICIEN. Serie Igualdad y Ciudadanía 13, 103-139. Barcelona: Diputación de Barcelona.

GONZÁLEZ ALCANTUD, José Antonio

1998 Antropología (y) política. Sobre la formación cultural del poder. Barcelona: Antrhopos.

SEN, Amartya

2006 Desarrollo y libertad, $8^{\text {a }}$. Edición, Bogotá: Planeta.

PROGRAMA DE NACIONES UNIDAS

1990 Informe de Desarrollo Humano. http: //hdr.undp.org/sites/default/files/hdr_1990_es_comVÁZQUEZ, Antonio

2000 "Desarrollo endógeno y globalización", en Eure 26, 79: 47-66.

2009 "Desarrollo Local, estrategia en tiempos de crisis", en Universitas Forum, 1, 2: 1-11.

TOURAINE, Alain

2011 Después de la crisis. Por un futuro sin marginación. Madrid: Paidós. 